between idiopathic polymyalgia rheumatica and hypothyroidism is unlikely.

1 Wiseman P, Stewart K, Rai GS. Hypothyroidism in polymyalgia rheumatica and giant cell arteritis. Br Med f 1989;298:647-9.

2 Grundy EN. Assessment of thyroid function. Brighton: University of Sussex, 1979:260-75. PhD Thesis.)
$3 \mathrm{Burgi} \mathrm{H}$. The thyroid gland. In: Labhart A, ed. Clinical endocrinology, theory and practice. 2nd ed. Berlin, Heidelberg: Springer Verlag, 1986: 181-348.

4 Dasgupta B, Duke O, Kyle V, Macfarlane DG, Hazleman BL, Panayi GS. Antibodies to intermediate filaments in polymyalgia rheumatica and giant cell arteritis: a sequential study. Ann Rheum Dis 1987;46:746-9.

(Accepted 28 February 1990)

\section{Reactivation of rheumatoid arthritis during continuous infusion of interleukin 2: evidence of lymphocytic control of rheumatoid disease}

\author{
M Lavelle-Jones, A Al-Hadrani, E M Spiers, \\ F C Campbell, A Cuschieri
}

Ninewells Hospital and Medical School, Dundee DD1 9SY

M Lavelle-Jones, FRCS, lecturer in surgery

A Al-Hadrani, FRCS, research fellow, department of surgery

E M Spiers, MRCP, registrar, department of pathology

F C Campbell, FRCS, senior lecturer in surgery

A Cuschieri, MD, professor of surgery

Correspondence to:

Professor Cuschieri.

Br.Med F 1990;301:97

Frequent toxic complications during bolus administration of interleukin 2 as immunotherapy for cancer led to the use of continuous infusion of the drug, which is better tolerated. We report on a patient with metastatic colorectal cancer whose rheumatoid arthritis recurred during continuous infusion of interleukin 2 .

\section{Case report}

A 57 year old woman with quiescent rheumatoid arthritis whose symptoms were controlled with paracetamol presented with weight loss and iron deficiency anaemia. Examination showed a large pelvic mass, and a poorly differentiated carcinoma of the sigmoid colon was confirmed by colonoscopy and biopsy. At laparotomy the disease was found to be extensive locally and to affect adjacent small bowel. There were multiple metastatic deposits in the right lobe of the liver. The sigmoid colon and the affected small bowel were resected, and gastrointestinal continuity was restored by two separate end to end anastomoses. Because of residual hepatic disease she was entered into a trial in which patients with advanced colorectal cancer were given a continuous infusion of recombinant interleukin $2\left(18 \times 10^{6} \mathrm{IU} / \mathrm{m}^{2} /\right.$ day for five days $)$ and sequential fluorouracil $\left(80 \mathrm{mg} / \mathrm{m}^{2}\right.$ weekly intravenous injection for three weeks) (Eurocetus EC-MP-004 trial). The first treatment cycle began four weeks after her operation.

Forty eight hours after the infusion of interleukin 2 was started the patient complained of a progressive, acute arthropathy affecting the knees, elbows, and neck; previously her wrists and metacarpophalangeal joints had been affected. Her serum concentration of rheumatoid factor had risen from 0 to $22 \times 10^{4} \mathrm{IU} / \mathrm{l}$ and the circulating concentration of $\mathrm{C}$ reactive protein from 31 to $120 \mathrm{mg} / \mathrm{l}$. The mean serum interleukin 2 concentration during the infusion was $24 \times 10^{3} \mathrm{IU} / 1$. Because of progressive pain, which did not resolve when the rate of the infusion was reduced or when naproxen $500 \mathrm{mg}$ twice daily was added, the infusion was stopped and her symptoms controlled with systemic steroids. Changes in circulating lymphocyte concentrations were consistent with those seen during treatment with interleukin 2 , the total lymphocyte count dropping from $2.4 \times 10^{9} / 1$ to a nadir of $0.6 \times 10^{9} / 1$ during infusion. When treatment was withdrawn a rebound lymphocytosis occurred $\left(4 \cdot 2 \times 10^{9} / 1\right)$ and the serum concentration of rheumatoid factor fell to $5 \times 10^{4}$ IU/l within 72 hours.

\section{Comment}

Clinical studies of bolus injections of interleukin 2 as immunotherapy have shown a multisystem toxicity related to the dose, the most serious effect being a microvascular capillary leak syndrome producing hypotension, oliguria, and pulmonary oedema. Constant infusions of interleukin 2 maintain the cytotoxic lymphoproliferative response and avoid these life threatening side effects. Because interleukin 2 acts by promoting an immune response to the tumour itself toxicities relating to disturbances in immune function are not unexpected. To our knowledge, this is the first report of an exacerbation of rheumatoid arthritis induced by interleukin 2. Current evidence supports the concept that the inflammatory response in rheumatoid arthritis is caused by a synovial infiltrate of activated inflammatory cells, including $\mathrm{T}$ lymphocytes, that secrete a variety of cytokines. ${ }^{\prime}$ Their importance in the pathogenesis of rheumatoid arthritis is supported by the clinical improvement seen in patients after drainage of the thoracic duct and lymphocytapheresis. ${ }^{2}$ Although controversy exists over the quantity of interleukin 2 in the rheumatoid joint, ${ }^{3}$ this cytokine may stimulate the functions of CD4 T cells, B cells, and macrophages locally with subsequent release of factors that mediate inflammation and rheumatoid factor. ${ }^{+}$This would explain the exacerbation of rheumatoid arthritis induced in our patient after infusion of a fairly large dose of interleukin 2 .

Our experience suggests that immunotherapy with interleukin 2 should be used with caution in patients with rheumatoid arthritis. These patients might derive benefit from an inhibitor of cyclo-oxygenase such as ibuprofen before and during treatment with interleukin 2 as ibuprofen has recently been shown to reduce the toxic effects associated with this treatment. ${ }^{5}$

1 Jira M, Malkovsky M, Denmen AM, et al. Lymphokine activated killer cell activity in rheumatoid arthritis. Clin Exp Immunol 1987;68:535-42.

2 Karsh J, Klippel JH, Plotz PH, et al. Lymphapheresis in rheumatoid arthritis. Arthritis Rheum 1981;24:867-73.

3 Buchan G, Barrett K, Fujita T, et al. Detection of activated T cell products in the rheumatic joint using cDNA probes to interleukin-2 (IL-2) receptor and IFN-gamma. Clin Exp Immunol 1988;71:295-301.

4 Weiss A. T lymphocytes. In: Kelly WN, Harris ED, Ruddy S, Sledge CB, eds. Textbook of rheumatology. Philadelphia: W B Saunders, 1989:148-61.

5 Eberlein TJ, Schoof DD, Michie HR, et al. Ibuprofen causes reduced toxic effects of interleukin 2 administration in patients with metastatic cancer. Arch Surg 1989;124:542-6

(Accepted 20 April 1990)

\section{Correction}

Somatostatin analogue treatment for malignant hypercalcaemia

An authors' error occurred in this short report by Dr $M$ Harrison and others (19 May, p 1313). The dosage of octreotide given was $50 \mu \mathrm{g}$ to $100 \mu \mathrm{g}$ twice a day and not $50 \mathrm{mg}$ to $100 \mathrm{mg}$ as published. 